\title{
Differential recall of central and peripheral details of emotional slides is not a stable phenomenon
}

Citation for published version (APA):

Wessel, J. P., van der Kooy, P. J., \& Merckelbach, H. L. G. J. (2000). Differential recall of central and peripheral details of emotional slides is not a stable phenomenon. Memory, 8(3), 8-2.

https://doi.org/10.1080/096582100387641

Document status and date:

Published: 01/01/2000

DOI:

10.1080/096582100387641

Document Version:

Publisher's PDF, also known as Version of record

\section{Please check the document version of this publication:}

- A submitted manuscript is the version of the article upon submission and before peer-review. There can be important differences between the submitted version and the official published version of record.

People interested in the research are advised to contact the author for the final version of the publication, or visit the DOI to the publisher's website.

- The final author version and the galley proof are versions of the publication after peer review.

- The final published version features the final layout of the paper including the volume, issue and page numbers.

Link to publication

\footnotetext{
General rights rights.

- You may freely distribute the URL identifying the publication in the public portal. please follow below link for the End User Agreement:

www.umlib.nl/taverne-license

Take down policy

If you believe that this document breaches copyright please contact us at:

repository@maastrichtuniversity.nl

providing details and we will investigate your claim.
}

Copyright and moral rights for the publications made accessible in the public portal are retained by the authors and/or other copyright owners and it is a condition of accessing publications that users recognise and abide by the legal requirements associated with these

- Users may download and print one copy of any publication from the public portal for the purpose of private study or research.

- You may not further distribute the material or use it for any profit-making activity or commercial gain

If the publication is distributed under the terms of Article $25 \mathrm{fa}$ of the Dutch Copyright Act, indicated by the "Taverne" license above, 


\title{
Differential recall of central and peripheral details of emotional slides is not a stable phenomenon
}

\author{
Ineke Wessel, Petra van der Kooy, and Harald Merckelbach \\ Maastricht University, The Netherlands
}

\begin{abstract}
A number of studies have reported that central information of an emotional scene is well retained, whereas peripheral details of such a scene are poorly recalled. Experiment 1 tested the hypothesis that attentional narrowing is responsible for this phenomenon. In addition, an attempt was made to increase the ecological validity of the experiment by giving extensive self-relevant instructions. Results showed that, although an emotional slide elicited eye-movements consistent with attentional narrowing, the corresponding recall patterns were absent. Experiments 2 and 3 explored some of the variables that might be responsible for the latter result. Experiment 2, relying on the original design of Christianson and E.F. Loftus (1991), found enhanced recall of central information of an emotional scene. Experiment 3 systematically varied stimulus exposure and interstimulus interval durations. However, the results of this experiment were rather complex and did not fully support the predicted differential recall patterns. Possible explanations for these findings are discussed. It is suggested that other methods (e.g. increasing levels of emotion rather than involvement) may be more suitable for testing the attentional narrowing hypothesis of emotional memory.
\end{abstract}

\section{INTRODUCTION}

In eyewitness literature, it is frequently claimed that not all details of emotional situations are remembered equally well. More specifically, it is thought that memory for the gist (central details) of an emotional event is relatively good, whereas memory for irrelevant information (peripheral details) is relatively poor (see, for overviews, Christianson, 1992; Heuer \& Reisberg, 1992). A common explanation for these recall patterns is inspired by Easterbrook's (1959) cue-utilisation hypothesis. For example, Christianson (1992) suggests that emotional arousal promotes attentional narrowing such that attention would be directed to central details, at the expense of attention for peripheral details. This attentional focus, in turn, would result in differential recall of central and peripheral information. Thus, according to the attentional narrowing hypothesis, two variables are important for emotional memory formation, namely physiological arousal and attention.

As for the first variable, detail memory studies consistently demonstrate that emotional scenes produce higher self-report ratings of emotionality (Christianson \& E.F. Loftus, 1987, 1991; Heuer \& Reisberg, 1990) or larger physiological responses (Burke, Heuer, \& Reisberg, 1992; Heuer \& Reisberg, 1990) than do neutral scenes. In line with the attentional narrowing hypothesis, these studies found enhanced memory for central details, whereas memory for peripheral details was relatively poor (Burke et al., 1992; Christianson \& E.F. Loftus, 1987, 1991; but see Heuer \& Reisberg, 1990).

The second variable involves visual attention. It is generally assumed that eye fixation patterns

Requests for reprints should be sent to I. Wessel, Department of Psychology, Maastricht University, P.O. Box 616, 6200 MD Maastricht, The Netherlands. Email: I.Wessel@Psychology.Unimaas.NL

The authors wish to thank Jos Adam and Fred Paas for providing and assisting with the Eyemark recorder, and Ger van Wunnik for giving technical assistance. We are grateful to Erik Schouten, Gerard van Breukelen, and Peter Muris for providing statistical advice. 
reflect visual attention (Christianson, Loftus, Hoffman, \& Loftus, 1991; G.R. Loftus, 1972; Loftus, Loftus, \& Messo, 1987). Studies measuring eye-movements suggest that compared to neutral scenes, emotional scenes elicit longer fixation durations (Loftus et al., 1987) or a higher frequency of fixations (Christianson et al., 1991; Loftus et al., 1987) on central features. In these studies it was found, again, that central details of emotional material are better retained (Christianson et al., 1991), whereas peripheral details are more poorly retained (Loftus et al., 1987) compared to neutral material.

Taken together, support for the attentional narrowing hypothesis comes from two sources: studies measuring memory for arousing stimuli and studies examining visual attention and memory. However, so far, no study has concurrently measured arousal, visual attention, and detail memory. In addition, two issues relevant to the attentional narrowing hypothesis warrant further exploration.

The first issue concerns ecological validity. A general criticism of laboratory studies on emotion and memory is that they are too far removed from real life and that generalising experimental data to emotional life events (e.g. trauma) is not justified (e.g. Terr, 1994; Yuille \& Tollestrup, 1992). Strictly speaking, this position implies that emotional memory can only be examined in field studies. However, this type of study may suffer from problems such as retrospective bias or circularity due to post-hoc categorisation of central and peripheral information (Christianson \& E.F. Loftus, 1990; Wessel \& Merckelbach, 1994). Because these problems can be circumvented in controlled experiments, it seems worthwhile to find approaches that increase the ecological validity of laboratory studies on emotion and memory. Yuille and Tollestrup (1992) argued that emotional intensity and involvement of the subjects are critical differences between experimental situations and real-life traumatic events. Obviously, ethical considerations preclude inducing intense emotion in college student samples. Thus, increasing the involvement of normal subjects in the experimental situation is one of the few options for researchers who attempt to increase the ecological validity of their experiments.

A second issue pertains to the question of whether attentional narrowing is restricted to emotional events. It could be argued that emotional events are not only emotional, but also quite unusual in the course of daily life. There are several reasons to believe that unusual stimuli are remembered or attended to differently from neutral stimuli. To begin with, studies of the socalled isolation effect show enhanced memory for outstanding stimuli in homogeneous context (see Hunt, 1995). Second, literature closely related to the topic of central and peripheral detail memory provides some evidence that unusualness rather than threat value underlies the phenomenon of weapon focus (Pickel, 1998). Third, eye-movement data indicate that people fixate longer and more often on unusual objects compared to objects that are to be expected given the context (G.R. Loftus \& Mackworth, 1978). In order to control the outstanding properties of an emotional stimulus, Christianson and colleagues included an unusual control condition in their experiments (Christianson \& E.F. Loftus, 1991; Christianson et al., 1991). On the whole, the results of these studies were rather complex. One study (Christianson et al., 1991) found that the unusual and neutral conditions yielded rather similar eyemovements and detail memory performance (i.e. relatively poor memory for central details compared to an emotional condition). In contrast, Christianson and E.F. Loftus (1991) reported that viewing the same unusual scene resulted in impaired recall of both central and peripheral items. Clearly, the influence of unusualness needs further clarification.

In the first experiment reported in this paper, an attempt was made to test the attentional narrowing hypothesis by concurrently employing measures of arousal, attention, and memory. As this experiment failed to find the anticipated recall patterns, two further experiments were conducted. These studies explored the circumstances under which differential recall of central and peripheral details occurs. In each experiment, participants were college students who saw either an emotional, unusual, or neutral situation. With the issue of ecological validity in mind, Experiments 1 and 3 sought to increase subjective involvement by giving participants extensive, selfrelevant instructions.

\section{EXPERIMENT 1}

The main purpose of Experiment 1 was to test the attentional narrowing hypothesis by concurrently employing measures of arousal, visual attention, and detail memory. More specifically, three predictions were tested. First, it was expected that 
an emotional image would elicit larger physiological arousal responses (i.e. skin conductance) than either an unusual or a neutral one. Second, with respect to eye-movements, it was predicted that the emotional scene would elicit longer fixations on the central item and shorter fixations on the peripheral item compared to the unusual and neutral conditions. The third prediction was that, relative to the neutral and the unusual conditions, the emotional condition would produce better memory for central information and impaired memory for peripheral information.

\section{Method}

Subjects. Subjects were 63 undergraduates at Maastricht University. Their mean age was 20 years (range 18-27 years). Subjects were randomly assigned to one of three conditions (Emotional Condition, $n=22$; Unusual Condition, $n=21$; Neutral Condition, $n=20$. They were paid for their participation.

Stimulus material. The stimulus material consisted of a thematic series of 15 slides. ${ }^{1}$ The slide series was about a student who was on the way to university to take an exam. The slides depicted typical scenes that a student would encounter in such a situation (e.g. a bedroom, a kitchen, a street, etc.). Each slide contained two critical items, one that was central and the other peripheral. The slide series were equal for three versions, with the exception of the eighth, critical slide. In this critical slide, the central detail varied across conditions. In the emotional version, a 9year-old girl was lying on a pedestrian crossing, bleeding from a head injury. In the unusual version, the same girl was seen lying on the pedestrian crossing in a gymnastic position (i.e. holding both legs in the air). In the neutral version, the girl was walking on the pedestrian crossing. The position of the girl on the pedestrian crossing and the angle from which the photograph was taken were iden-

This newly developed stimulus material was modelled after that of Christianson and E.F. Loftus (1991). In a separate pilot study $(n=33)$, characteristics of this material (e.g. emotionality, credibility, etc.) were evaluated. The results of this preliminary study confirmed that the emotional slide was rated as less pleasant and more emotional than the unusual and the neutral slides. In addition, the unusual slide matched the emotional slide in terms of its outstanding (i.e. attentioncatching) properties. Further information on the slide series and its properties are available on request. tical in each version. A pink bicycle standing near the right margin of the slide served as peripheral item in each of the critical slides.

Apparatus. A Kodak carousel projected slides on a white wall approximately two metres in front of the subjects. The projected images were $125 \times 85 \mathrm{~cm}$

During slide presentation, Skin Conductance Responses (SCRs) were recorded through two Beckman Ag-AgC electrodes attached to the second and third finger of the subject's nondominant hand. Electrodermal recording sites were cleansed with distilled water. Electrodes were connected to a Schwartzer EDA coupler. To record SCRs, the method of constant voltage $(0.5 \mathrm{~V})$ was used.

Eye-movements during slide presentation were registered using an Eyemark recorder (model V, NAC Inc.). This recorder projects infra-red lights on subjects' corneas, which are transformed into fixation spots. Fixation spots were imposed on the slide image recorded by a video camera attached to subjects' foreheads. Subjects' heads were fixated during slide presentation in order to avoid head movements.

Procedure. Subjects were tested individually in a sound-attenuated, dimly lit room. Upon arrival in the laboratory, subjects were told that the experiment involved recording of their physiological reactions to a series of slides. No explicit mention of a memory task was made. Next, SCR electrodes were attached and the Eyemark recorder was positioned and calibrated.

Following this, subjects received extensive selfrelevant instructions. They were instructed to imagine that they were the main character in a slide story. They were told that every scene in the story was photographed from their perspective, as if they were seeing it through their own eyes. In addition, to aid imagination, subjects received a tape-recorded instruction immediately before presentation of the slides (see Appendix).

Immediately after the tape-recorded instruction, the first slide (depicting a bedroom) was presented. Slides were presented for 4 seconds, and intervals between slides were 6.6 seconds. After slide presentation, the SCR electrodes and the Eyemark recorder were removed. Next, subjects completed filler questionnaires for 10 minutes.

Subsequently, subjects were given three memory tasks. First, they completed a Free Recall task 
that asked for a brief description of all the slides they had seen. Second, a Cued Recall task was administered. Subjects were shown a series of 15 slides, similar to the first series, with the exception that the central and peripheral items were removed. During presentation of each slide, subjects wrote down which items they thought were missing from that slide. Third, subjects completed a Detailed Cued Recall task. For this purpose, the critical eighth slide without the central girl and peripheral bicycle was presented. This time, subjects were asked to describe the missing items in as much detail as possible, with respect to colour, shape, size, position, and so forth. For completion of all recall tasks, subjects were allowed as much time as they needed. Finally, they were debriefed and were asked not to discuss the purpose of the study with other students.

Scoring of physiological data. SCRs were measured in microsiemens and were defined as the largest response with onset during slide presentation. SCRs to the critical slide were square root transformed $(\sqrt{\mathrm{SCR}})$ in order to normalise the distribution. Due to apparatus failure, SCRs of one subject in the unusual condition were lost.

Eye-movements were scored as follows. First, a digital clock was recorded on the videotapes, which indicated time with an accuracy of 0.01 seconds. Then, the videotapes were played back frame by frame. Three observers simultaneously scored the amount of time subjects looked at the central girl or the peripheral bicycle. In order to do so, the observers had to agree about the time at which the subjects' eyes arrived at a particular item and the time at which the eyes shifted away again. Fixations within a particular item (e.g. shifting the eyes from the girl's head to her feet) were not scored separately, because interfixation distances were too short to obtain accurate judgements. Due to calibration problems with the Eyemark recorder, the data of 12 subjects were unreliable (emotional condition, $n=3$; unusual condition, $n=6$; neutral condition, $n=3$ ).

Scoring of Memory Data. Following Christianson and E.F. Loftus (1991, experiment 1), we adopted a strict criterion for evaluating fee and cued recall. That is, central items were scored correct if subjects explicitly mentioned "girl" or indicated sex. For the peripheral items, the response "bicycle" was scored correct.

The more specific data collected with the Detailed Gued Recall test were scored in accor- dance with the definition of Christianson (1992, p.291) that central information is "information that is connected with the source of the emotional arousal (i.e. the gist of the event and its central details)", while peripheral information refers to "information that is irrelevant or spatially peripheral to the source of the emotional arousal." Thus, although certain details of the central girl (e.g. colour of clothing, position on the crossing) may be considered thematically irrelevant, they were treated as central because they were associated with the central girl. For both the emotional and the unusual slides, there was a maximum of 18 scorable characteristics of the central girl. For the neutral slide, there was a maximum of 15 possible details associated with the central girl. The maximum of scorable central elements differed across conditions because characteristics such as blood (emotional slide) and smiling face (unusual slide) were absent in the neutral slide. However, for the emotional, unusual, and neutral slides, there was a maximum of 12 scorable elements of the peripheral bicycle. To correct for different base-rates, subjects' responses on the detailed cued recall test were transformed into proportions of the maximum number of characteristics that could be maintained for the item of interest (i.e. 18, 15, or 12). In order to facilitate comparisons with the original Christianson and E.F. Loftus (1991) experiment, we also looked at the number of subjects who spontaneously mentioned one specific characteristic during detailed recall, viz. the colour of the central girl's shirt and/or the colour of the peripheral bicycle.

\section{Results}

$\sqrt{S C R s .} \quad$ Mean $\sqrt{ } \mathrm{SCRs}$ were $0.73(S D=0.58)$, $0.38(S D=0.36)$, and $0.23(S D=0.27)$ in the emotional, unusual and neutral conditions, respectively. A one-way ANOVA showed a significant difference between conditions, $F(2,59)=7.35, \quad p<.01$. Planned comparisons revealed that the emotional slide elicited significantly larger $\sqrt{ } \mathrm{SCRs}$ than either the unusual or the neutral slide $(p \mathbf{s}<.05)$.

Eye movement data. Mean fixation times were subjected to a 3 (conditions) $\times 2$ (central vs peripheral detail) ANOVA with repeated measures on the last factor. This yielded significant main effects for condition, $F(2,48)=5.21, p<.01$, and detail, $F(1,48)=42.02, p<.001$. In addition, 
the critical interaction effect was significant, $F(2,48)=4.68, p<.05$ (see Figure 1). To break down this interaction, three separate 2 (condition) $\times 2$ (detail) repeated measured ANOVAs were conducted. Relative to the neutral condition, the emotional condition was characterised by longer fixations on the central girl and shorter fixations on the peripheral bicycle, as evidenced by a significant interaction effect, $F(1,34)=7.11$, $p<.05$. Contrary to expectations, mean fixation time patterns in the emotional and unusual conditions did not differ, $F(1,32)=1.97, p=.17$. Moreover, the group by detail interaction for the unusual and neutral groups was marginally significant, $F(1,30)=4.16, p=.05$.

Recall. Results of the memory tests are presented in Table 1. For free recall, there was a significant difference between conditions in terms of number of subjects reporting the central girl, $\chi^{2}(2)=7.24, p<.05$. Separate $\chi^{2}$ tests showed that compared to the neutral condition, significantly more subjects in the unusual condition reported the central girl, $\chi^{2}(1)=7.43, p<.01$. The emotional condition did not differ from either the unusual or neutral condition. In addition, the cued recall test displayed no significant differences between conditions with regard to the central detail, $\chi^{2}(2)=3.91, p=.14$. As for the peripheral bicycle, neither free recall, $\chi^{2}(2)=0.29, p=.86$, nor cued recall $\chi^{2}(2)=0.59, p=.74$, revealed differences between conditions.

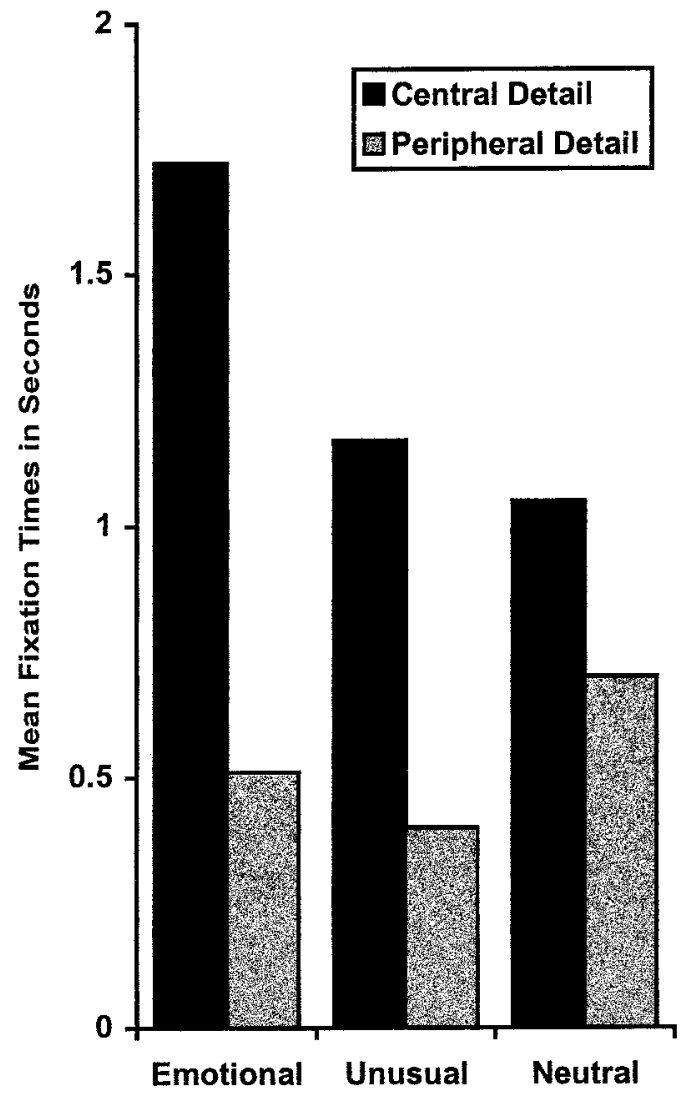

Figure 1. Mean time per fixation on the central and peripheral detail in the emotional, unusual, and neutral conditions in Experiment 1.

TABLE 1

Recall of central and peripheral information of the critical slide in Experiment 1

\begin{tabular}{|c|c|c|c|}
\hline & $\begin{array}{c}\text { Emotional } \\
\text { Condition } \\
(\mathrm{n}=22)\end{array}$ & $\begin{array}{c}\text { Unusual } \\
\text { Condition } \\
(\mathrm{n}=21)\end{array}$ & $\begin{array}{c}\text { Neutral } \\
\text { Condition } \\
(\mathrm{n}=20)\end{array}$ \\
\hline \multicolumn{4}{|l|}{ Free Recall ${ }^{a}$} \\
\hline Central & 72.7 & 95.2 & 60.0 \\
\hline Peripheral & 45.5 & 38.1 & 45.0 \\
\hline \multicolumn{4}{|l|}{ Cued Recall ${ }^{a}$} \\
\hline Central & 72.7 & 95.2 & 80.0 \\
\hline Peripheral & 68.2 & 57.1 & 65.0 \\
\hline \multicolumn{4}{|c|}{ Detailed Cued Recall ${ }^{b}$} \\
\hline Central & $0.28(0.11)$ & $0.25(0.10)$ & $0.26(0.11)$ \\
\hline Peripheral & $0.22(0.18)$ & $0.21(0.16)$ & $0.20(0.16)$ \\
\hline Colour Shirt ${ }^{\mathrm{a}}$ & 22.7 & 4.8 & 20 \\
\hline Colour Bicycle & 45.5 & 38.1 & 55 \\
\hline
\end{tabular}

\footnotetext{
${ }^{a}$ Percentage of subjects who answered correctly.

${ }^{\mathrm{b}}$ Mean proportion characteristics. Standard deviations are in parentheses.
} 
For detailed cued recall, a 3 (conditions) $\times 2$ (central vs peripheral detail) ANOVA with repeated measures on the last factor was performed on the proportion data. There was a significant main effect of detail, $F(1,60)=5.70$, $p<.05$, whereas the main effect of condition was not significant, $F(2,60)=0.33, p=.72$. The critical interaction effect indicating differential recall of central and peripheral characteristics across conditions, failed to reach significance, $F(2,60)=0.07$, $p=.93$. As for the spontaneously mentioned colour information during detailed cued recall, there were no differences between the conditions. This absence of reliable differences was true for the central girl's shirt, $\chi^{2}(2)=2.97, p=0.23$; as well as for the peripheral bicycle, $\chi^{2}(2)=1.18, p=0.55$.

The attentional narrowing hypothesis predicts that a high level of physiological arousal leads to attentional narrowing, which, in turn, has ramifications for detail memory. Thus, associations between $\sqrt{ }$ SCRs, fixation times and recall data were examined. More specifically, Pearson product-moment correlations for associations involving $\sqrt{S C R s}$, fixation times, and detailed cued recall were computed, whereas biserial correlations were calculated for associations involving free and cued recall. $\sqrt{S C R}$ and fixation times for the central girl were found to be correlated, $r(50)=.26, p<.05$, one-tailed. However, no association between $\sqrt{ } \mathrm{SCRs}$ and peripheral fixation times was found, $r(50)=-.09$. Peripheral fixation times were positively correlated with cued recall and detailed cued recall of the peripheral bicycle, $r(51)=.33, p<.01$ and $r(51)=.25, p<.05$, respectively. Yet, neither $\sqrt{ } \mathrm{SCR}$ s nor fixation times correlated with any of the recall tests for central information. Likewise, no associations emerged between $\sqrt{ }$ SCRs and recall of peripheral information.

Table 1 suggests that about $30 \%$ of the subjects in the emotional condition failed to recall the central girl, even when provided with cues. Possibly, this high percentage has to do with the strict criterion on which we relied. To elucidate this issue, non-responses (i.e. failing to mention the central girl) were considered in more detail.

Table 2 shows that during free recall, a large majority of the non-responders in the emotional condition did mention that they had seen a child in the critical slide. Only in the neutral condition did a substantial minority of the subjects (20\%) fail to mention the central girl. During cued recall, all subjects at least said that they had seen a child in the target slide. We also calculated the percentage of subjects that spontaneously mentioned the sex of the child when asked to give a specific description during the detailed cued recall test. Only two subjects in the emotional condition said they had seen a child; all other subjects specified the sex of the child.

Another point that can be inferred from Table 1 is that the proportion of subjects who spontaneously mentioned colour is relatively low. This is especially true for the colour of the central girl's shirt. A closer look at the non-responses revealed that a considerable percentage of the subjects specified the wrong colour $(40.9 \% ; 38.1 \%$ and $45 \%$ in the emotional, unusual, and neutral conditions, respectively). For the peripheral bicycle, this type of error was relatively rare in the emotional $(4.5 \%)$ and neutral $(10 \%)$ conditions. However, in the unusual condition, 33\% mentioned the wrong colour for the bicycle.

TABLE 2

Type of responses given in Experiment 1

\begin{tabular}{llccc}
\hline \multirow{2}{*}{ Recall Test } & Condition & No Response & $\begin{array}{c}\text { Response } \\
\text { Girl }\end{array}$ & Child \\
\hline Free Recall & Emotional & 4.5 & 72.7 & 22.7 \\
& Unusual & - & 95.2 & 4.8 \\
& Neutral & 20 & 60 & 20 \\
Cued Recall & Emotional & - & 72.7 & 27.3 \\
& Unusual & - & 95.2 & 4.8 \\
Detailed Cued Recall & Neutral & - & 80 & 20 \\
& Emotional & - & 90.9 & 9.1 \\
& Unusual & - & 100 & - \\
& Neutral & - & 100 & - \\
\hline
\end{tabular}




\section{Discussion}

In line with predictions flowing from the attentional narrowing hypothesis of emotional memory, subjects in the emotional condition displayed substantially higher arousal responses (SCRs), looked for longer durations at the central girl, and spent less time looking at the peripheral bicycle than subjects in the neutral condition. Nevertheless, the predicted differential recall patterns did not occur. That is, compared to the control conditions, subjects in the emotional group did not show enhanced memory for central information, nor did they display impaired memory for peripheral information. In addition, only for peripheral information were modest associations found between fixation times and recall, while such correlations failed to occur for tests involving central detail recall. Clearly, then, differential allocation of attention at the time of stimulus processing does not imply a differential recall pattern of central and peripheral details. Thus, the current findings underline the conclusion drawn earlier by Christianson (Christianson, 1992; Christianson et al., 1991) that the link between attentional narrowing and emotional memory is imperfect. Note that this imperfect link cannot be attributed to the encoding stage. From Table 2, it can be concluded that initial failures to mention the central character during free recall cannot be accounted for in terms of a failure to encode the central item During detailed cued recall, all subjects mentioned having seen a girl or child.

As for the role of unusualness, the eye-movement patterns in the unusual condition did not differ from those in the emotional condition. Moreover, compared to the neutral condition, the unusual group was more likely to mention the central girl at free recall. Thus, on these measures, the unusual group came closer to the emotional group than to the neutral group.

All in all, the present findings are difficult to reconcile with earlier studies claiming that central details of an emotional stimulus are relatively well retained, while peripheral details of such a stimulus are relatively poorly retained (e.g. Christianson \& E.F. Loftus, 1991). These conflicting findings may reflect procedural differences. For example, the present approach differs in several respects from the design employed by Christianson and E.F. Loftus (1991). To begin with, Christianson and E.F. Loftus tested recall of one particular character- istics of their central and peripheral items (i.e. colours), whereas we mainly looked at the response categories of "girl" and "bicycle". Note, however, that in the present study, inspection of spontaneously mentioned colour information during detailed recall revealed no differences between emotional, unusual, and neutral conditions. Still, spontaneous descriptions may not be comparable to answering specific questions about colour information. Apart from a high rate of erroneous colour recall, our data also showed a high rate of subjects who failed to mention colour at all. It remains possible that the latter category of subjects would answer correctly when specifically asked about colours.

A second issue is that we used substantially longer presentation and interstimulus times than Christianson and E.F. Loftus did. It is conceivable that differences in detail memory are more pronounced when subjects have less time for encoding. A third procedural difference is that Christianson and E.F. Loftus merely instructed their subjects to attend closely to the stimuli, whereas subjects in the present experiment received extensive identification instructions.

A final issue has to do with the potential lack of power of our study. Although the current study relied on a sample size $(n=63)$ that was comparable to that of the Christianson and EF. Loftus (1991, experiment 1) study (i.e. $n=60$ ), these authors found medium effect sizes for differential recall of central and peripheral information (i.e. $w=.34$ for the central woman; $w=.30$ for the peripheral car). With such effects, our sample size allowed for a statistical power of .55 .

A second experiment was conducted in order to explore whether differential recall patterns could be replicated when the instructions, short stimulus exposure, and interval times of Christianson and E.F. Loftus (1991) are employed. Also, sample size was increased so as to ensure a power of at least .70.

\section{EXPERIMENT 2}

The purpose of Experiment 2 was to replicate the Christianson and E.F. Loftus (1991) study, using the stimulus material of Experiment 1. Specifically, subjects were merely instructed to attend to the slides, which were presented for relatively short durations. In addition, only memory for the colours associated with the central and peripheral detail information was tested. 


\section{Method}

Subjects. Subjects were 86 undergraduate volunteers. Their mean age was 20.6 years (range 18-36 years). They were assigned to one of three conditions (Emotional Condition, $n=32$; Unusual Condition, $n=24$; Neutral Condition, $n=30$.

Stimulus material and apparatus. The stimulus material consisted of the thematic slide series described in Experiment 1. A Kodak carousel projected slides onto a screen in front of a classroom.

Procedure. Subjects were tested in a classroom after an introductory psychology course about an unrelated topic. They were asked to participate in a short experiment. Next, the class was divided into three groups. One group was tested at a time, while the subjects in the other groups left for a coffee break. First, the emotional condition was run, then the neutral version, and finally the unusual condition.

Subjects were told that they would see a series of slides and afterwards would perform a drawing task. Before the slide series was projected, subjects were informed that the slides depicted situations one could encounter on the way to university to take an exam. Unlike Experiment 1, no further instructions were given. Next, the slides were presented. Each slide was presented for three seconds and interstimulus intervals were one second (see Christianson \& E.F. Loftus, 1991, Experiment 2). Immediately after slide presentation, subjects performed a filler task. This task consisted of copying geometric figures that were presented on the screen by an overhead projector. Subjects were given 30 seconds for each figure. In total, they copied eight figures. Next, a surprise cued recall task was administered. For this purpose, a version of the critical eighth slide was presented, from which the central girl and the peripheral bicycle were removed (see Detailed Gued Recall task, Experiment 1). Subjects were asked to write down the colour of the blouse that the person missing from the slide was wearing. Next, they wrote down the colour of the missing bicycle. They were allowed 40 seconds for each question. Subjects were asked not to discuss the experiment with other students. To prevent them from talking, they left through the emergency exit, while the next group waited in front of the opposite main entrance.
TABLE 3

Recall of colour information in Experiment 2

\begin{tabular}{lccc}
\hline Colour Recall & $\begin{array}{c}\text { Emotional } \\
\text { Condition } \\
(\mathrm{n}=32)\end{array}$ & $\begin{array}{c}\text { Unusual } \\
\text { Condition } \\
(\mathrm{n}=24)\end{array}$ & $\begin{array}{c}\text { Neutral } \\
\text { Condition } \\
(\mathrm{n}=30)\end{array}$ \\
\hline Central & 65.6 & 33.3 & 33.3 \\
Peripheral & 34.4 & 41.7 & 43.3 \\
\hline
\end{tabular}

\section{Results and discussion}

Table 3 summarises the percentages of subjects who accurately reported the colour of the central girl's blouse (white) and the colour of the peripheral bicycle (pink/red). Conditions significantly differed with regard to memory for the central detail, $\chi^{2}(2)=8.45, p<.05$. Separate $\chi^{2}$ analyses indicated that subjects in the emotional condition more often reported the accurate colour of the blouse than subjects in either the unusual condition, $\chi^{2}(1)=5.73, p<.05$, or the neutral condition, $\chi^{2}(1)=6.46, p<.05$. As for the colour of the peripheral bicycle, results were in the expected direction, but failed to reach significance, $\chi^{2}(2)=0.58, p=.75$.

In sum, results on central detail information are in line with those reported by Christianson and E.F. Loftus (1991). As for peripheral detail information, there were slight but nonsignificant differences in the expected direction. In addition, inspection of Table 3 reveals that the emotional group more frequently reported the central detail than the peripheral detail. The unusual and neutral groups showed a reverse recall pattern. Taken together, Experiment 2 partially replicates the differential recall pattern observed in previous work on emotional detail memory (e.g. Burke et al., 1992; Christianson \& E.F. Loftus, 1991).

\section{EXPERIMENT 3}

The results of Experiment 2 suggest that when subjects are tested under similar conditions as in the Christianson and E.F. Loftus (1991) study, recall of a central detail of an emotional stimulus is enhanced as opposed to that of an unusual or neutral stimulus. However, Experiment 1 did not find evidence for such differential recall, although that experiment found clear indications for attentional narrowing (i.e. larger SCRs to the emotional slide and longer fixations on the central 
part of the slide). Although Experiment 1 relied on the same stimulus material as Experiment 2, the experimental circumstances (i.e. instructions, stimulus durations, and interstimulus intervals) were quite different. A plausible interpretation of the conflicting results of Experiments 1 and 2 is one in terms of stimulus exposure time and interstimulus intervals. Keeping the attentional narrowing hypothesis in mind, it is conceivable that longer durations undermine systematic effects of attentional direction on recall. That is, effects of differential attentional focus on emotional and neutral material occurring in the first few moments of stimulus presentation might be overruled when longer presentation times provide subjects in one group with the opportunity to catch up with the other group. Inspired by the findings of Experiment 1 that many subjects recalled erroneous colour information, another explanation would be that longer stimulus durations and interstimulus intervals give rise to more extensive elaboration. This might interfere with memory for perceptual details such as colour. These considerations suggest that a differential recall pattern that favours central detail information occurs with shorter rather than with longer presentation times. This speculation was tested in a third experiment. As increasing ecological validity through self-relevant instructions was an important aim of Experiment 1, similar instructions were employed. At the same time, stimulus durations and interstimulus intervals were systematically varied. Because the main purpose of Experiment 3 was to examine whether stimulus durations are responsible for the absence of differential recall patterns in Experiment 1, we did not obtain physiological measures.

\section{Method}

Subjects. Subjects were 180 undergraduates. Their mean age was 18.8 years (range 17-27 years). Subjects were randomly assigned to one of six conditions (see later; $n=30$ in each condition). They were tested either individually or in small groups with a maximum of three subjects in each group. Subjects were paid for their participation.

Stimulus material and apparatus. Stimulus material was identical to that used in Experiments 1 and 2. A Kodak carousel projected slides onto a white wall, approximately two metres in front of the subjects. The size of the projected image was
$125 \times 85 \mathrm{~cm}$. Stimulus durations and interstimulus intervals were regulated by a Compaq deskpro 486 personal computer, controlling a Compur shutter.

Procedure. Subjects were tested in a soundattenuated, dimly lit room. Upon arrival in the laboratory, subjects were told that the purpose of the experiment was measuring physiological reactions (heart rate) while viewing slides. Then, a plethysmograph was attached to one of the subject's index fingers. This transducer was not connected to any measurement device, but was intended to provide a credible cover story. The cover story was introduced to prevent subjects from expecting some kind of memory test. Next, identification instructions were given in the same fashion as in the preliminary study and Experiment 1 .

Immediately following instructions, the slide series was presented. Subjects saw either the emotional, unusual, or neutral version of the slide series. Each version was presented under either of two conditions. In the long presentation/ISI condition, slides were shown for 4 seconds and interstimulus intervals were 6.6 seconds (see Experiment 1). In the short presentation/ISI condition, slide duration was 3 seconds and interstimulus intervals were set at 1 second (see Experiment 2). Thus, there were six conditions in a 3 (versions) $\times 2$ (presentation times) betweensubjects design.

After slide presentation, subjects completed some filler questionnaires in another room. The filler task took 10 minutes. Following this, the three recall tasks described in Experiment 1 (i.e. Free Recall, Cued Recall, and Detailed Cued Recall) were administered. Next, subjects answered two open-ended questions about the colours of the central girl's blouse and the peripheral bicycle (Additional Questions). Finally, subjects were debriefed and paid. The total procedure took about 45 minutes.

\section{Results}

Free recall, cued recall, and additional questions. Scoring of the memory data followed a similar procedure as that employed in Experiment 1. In order to explore the effect of presentation times and interstimulus interval durations on recall, logistic regression analyses were performed on memory tasks involving dichotomous variables 
(i.e. Free Recall, Gued Recall, and Additional Questions). Performance on the various recall tasks concerning either the central girl or the peripheral bicycle were dependent variables, whereas version (emotional vs unusual vs neutral), presentation/ISI duration (short vs long), and the version by presentation/ISI duration interaction served as predictors. Table 4 shows the results of the various recall tasks.

Central girl. For Free Recall, the logistic regression analysis rendered a borderline significant interaction term of presentation/ISI time and the contrast between the emotional and unusual version, $B=1.55$, $s e=0.82, p=0.06$. Thus, the unusual version tended to produce more reports of the central girl than the emotional version during short, but not during long presentation/ISI times.

Logistic regression analysis of Cued Recall results did not show any significant interactions between presentation/ISI times and version. However, the presentation/ISI time main effect was marginally significant, $B=-0.98$, se $=0.54$, $p=.07$, indicating that long presentation/ISI times tended to elicit more frequent reports of the central girl than short presentation/ISI times. Furthermore, significant effects occurred for the contrasts between the emotional and unusual versions, $B=-1.52$, se $=0.59, p<.01$, and the emotional and neutral versions, $B=-1.32$, $s e=0.57, p<.05$. Thus, overall, the emotional version was associated with poorer performance than the other versions.

As for the colour of the central girl's blouse (Additional Questions), no significant interaction between presentation/ISI times and version occurred. The contrast between the emotional and unusual versions reached borderline significance, $B=1.06$, se $=0.62, p=.09$. Thus, the emotional version tended to elicit more frequent reports of the accurate colour of the blouse than the unusual version.

Peripheral bicycle. Logistic regression of the Free Recall results rendered no significant main effects or interactions.

Although there were no significant interactions for Cued Recall, the contrast between the emotional and unusual version reached borderline significance, $B=-1.2$, se $=0.62, p=.05$. Thus, overall, subjects who saw the unusual version tended to outperform subjects who saw the emotional version in reporting the peripheral bicycle.

No significant main or interaction effects were found for reporting the colour of the bicycle (Additional Questions).

TABLE 4

Recall in Experiment 3 as a function of presentation/ISI duration

\begin{tabular}{|c|c|c|c|c|c|c|}
\hline & Short & entation/ISI D & ration & Long & entation/ISI D & ation \\
\hline & $\begin{array}{c}\text { Emotional } \\
\text { Version }\end{array}$ & $\begin{array}{l}\text { Unusual } \\
\text { Version }\end{array}$ & $\begin{array}{l}\text { Neutral } \\
\text { Version }\end{array}$ & $\begin{array}{c}\text { Emotional } \\
\text { Version }\end{array}$ & $\begin{array}{l}\text { Unusual } \\
\text { Version }\end{array}$ & $\begin{array}{l}\text { Neutral } \\
\text { Version }\end{array}$ \\
\hline Free Recall ${ }^{a}$ & & & & & & \\
\hline Central $^{\mathrm{b}}$ & $50(36.7)$ & $80(3.3)$ & 56.7 (16.7) & $73.3(23.3)$ & 70 (16.7) & $73.3(20)$ \\
\hline Peripheral & 10 & 20 & 6.7 & 16.7 & 36.7 & 13.3 \\
\hline Cued Recall ${ }^{a}$ & & & & & & \\
\hline Central $^{\mathrm{b}}$ & $46.7(46.7)$ & $80(20)$ & 76.7 (16.7) & 70 (26.7) & 80 (13.3) & 86.7 (10) \\
\hline Peripheral & 16.7 & 40 & 13.3 & 30 & 53.3 & 13.3 \\
\hline Detailed Cued & & & & & & \\
\hline Central & $0.23(0.14)$ & $0.24(0.09)$ & $0.24(0.13)$ & $0.23(0.12)$ & $0.27(0.12)$ & $0.23(0.11)$ \\
\hline Peripheral & $0.07(0.13)$ & $0.11(0.11)$ & $0.05(0.13)$ & $0.07(0.11)$ & $0.14(0.14)$ & $0.05(0.13)$ \\
\hline Colour Recall & & & & & & \\
\hline Central & 36.7 & 16.7 & 26.7 & 26.7 & 13.3 & 20 \\
\hline Peripheral & 13.3 & 26.7 & 13.3 & 13.3 & 46.7 & 10 \\
\hline
\end{tabular}

$\mathrm{N}=30$ in every condition.

${ }^{\mathrm{a}}$ Percentage of subjects.

${ }^{\mathrm{b}}$ Percentages of subjects who gave a general (child, person) or erroneous (boy) response are in parentheses.

${ }^{c}$ Proportion correct characteristics. Standard deviations are in parentheses. 
Detailed cued recall. For the Detailed Cued Recall test, data were first transformed into proportions (see Experiment 1). Next, a 2 (conditions: long vs. short presentation/ISI) $\times 3$ (versions: emotional, unusual, neutral) $\times 2$ (detail: central vs peripheral) ANOVA with repeated measures on the last factor was performed. No significant interactions were obtained. However, significant main effects of version, $F(1,174)=5.66, p<.01$ and detail, $F(1,174)=173.44, p<.001$, emerged. Separate $t$-tests were performed to break down the main effect of version. Subjects who saw the unusual version reported significantly more characteristics than subjects who saw either the emotional version, $t(118)=-2.51, p<.05$, or the neutral version, $t(118)=3.24, p<.01$. No differences emerged between the emotional and the neutral versions.

As in Experiment 1, we used a rather strict scoring criterion for the central item (i.e. "girl"). Table 4 also shows the percentage of subjects who gave a response other than "girl" (i.e. either a general or an erroneous response) on free and cued recall for the central item. Again, it appears that many non-responders gave a more general (i.e. "child" or "person") or wrong response (i.e. "boy") rather than failing to mention the central person. During the detailed cued recall, almost all subjects in the unusual and neutral conditions accurately specified sex of the central child (96.7\% and 95\%, respectively). Interestingly, subjects in emotional condition were considerably less accurate, $\chi^{2}(2)=11.82, p<.01$, in that $20 \%$ of them failed to mention the girl.

\section{Discussion}

The main results of Experiment 3 can be summarised as follows. First, no support was found for the assumption that relatively long stimulus and interstimulus interval durations undermine differential recall of central and peripheral details of emotional material. At best, there were a few nonsignificant trends in that direction. That is, during short presentations and interstimulus intervals, the emotional version tended to elicit poorer free recall of the central girl than the unusual version, but this recall pattern was absent during long presentation and interstimulus durations. In addition, the long presentation/ISI condition tended to elicit better cued recall of the central girl than the shorter presentation/ISI condition.
Second, contrary to expectations, subjects who saw the emotional version displayed poorer cued recall of the central girl than subjects who saw either the unusual or neutral version. It should be noted, though, that the poor reproduction of the central girl in the emotional condition was not linked to an absolute failure of recall. Rather, it reflects a tendency to give more general responses. Further, the unusual group recalled more details (i.e. Detailed Cued Recall) than either of the two other groups. One could argue that the detailed cued recall scores for the central features of the neutral slide should be interpreted with caution because the neutral slide had less codable characteristics of the central girl than the emotional and unusual slides (i.e. 15 vs 18). Note however, that the problem does not exist for comparisons involving the emotional and unusual conditions.

Still, the emotional group more often provided an accurate report of the colour associated with the central item than the unusual group. Likewise, the data presented in Table 4 suggest that the unusual condition displayed better peripheral colour recall than the other two groups. This point is further underscored by the results of a conditional regression analysis. ${ }^{2}$ However, this differential pattern of colour recall seems weaker than that found in Experiment 2. In the current experiment roughly one third of the subjects in the emotional condition accurately recalled the central colour, whereas in Experiment 2 almost two-thirds of the emotional group did so. Thus, some trends in the present data are in line with the

\footnotetext{
${ }^{2}$ To test the interaction between version (emotional, unusual, neutral) and type of details (central vs peripheral), responses to the Additional Questions were subjected to a conditional logistic regression analysis (Hosmer \& Lemeshow, 1989). The logic behind this analysis is as follows. Given that the outcomes in the current experiment were dichotomous (i.e. recall vs no recall), only those subjects who correctly recalled one colour, but not the other, were informative to a test of the within-subject effect under consideration (i.e. central vs peripheral recall). By restricting the conditional logistic regression analysis to those subjects only, the dependent variable reflected the probability of correct recall of the central colour, given that recall was successful for either the colour of the central girl's blouse $o r$ the colour of the peripheral bicycle. Predictors were slide version (emotional, unusual, neutral), presentation duration (short vs long), and the version by presentation duration interaction. Neither stimulus duration, nor the interaction between slide version and stimulus duration affected colour recall ( $p=.34$, and $p=.67$, respectively). However, the critical main effect of slide version (reflecting a version by type of detail interaction) attained significance, $p<.05$.
} 
expected differential recall patterns, but they are not very pronounced and are limited to comparisons involving the unusual condition.

\section{GENERAL DISCUSSION}

The attentional narrowing hypothesis predicts that under conditions of high physiological arousal, attention will be focused on the central aspects of an event, at the cost of attention for peripheral information. This would produce differential recall of central and peripheral aspects of an event. The primary aim of Experiment 1 was to test this hypothesis in a student sample. An unusual condition was included to control for the outstanding properties of emotional material. Furthermore, we sought to increase ecological validity by giving subjects extensive self-relevant instructions.

In Experiment 1, part of the attentional narrowing hypothesis was supported in that compared to the neutral condition, the emotional group was more aroused and showed eye-movement patterns indicative of attentional narrowing. Nevertheless, the emotional group failed to display the expected differential recall patterns. To further explore the experimental parameters that might be responsible for these results, two additional experiments were conducted.

Experiment 2 followed the design employed by Christianson and E.F. Loftus (1991) as closely as possible. With this set-up, enhanced recall of the central detail was found in the emotional group. Thus, the findings of Experiment 2 demonstrate that the lack of differential recall in Experiment 1 cannot be interpreted as an artefact of our newly developed stimulus material. To explore whether long stimulus exposure and interstimulus interval durations might overshadow effects of differential attention allocation, durations were systematically varied in Experiment 3. Results of Experiment 3 strongly suggest that such variations have little or no impact on recall patterns. In line with the results of Experiment 1, the emotional group did not display enhanced memory for central or impaired memory for peripheral information. However, when they were specifically asked to provide colour information, the emotional group tended to display the expected recall pattern in comparison to the unusual group. However, this pattern was less pronounced than that obtained in Experiment 2.

Taken together, the experimental circumstances created in Experiment 2 were most likely to yield recall patterns consistent with results that have repeatedly been found in previous studies (see Christianson, 1992), namely more accurate recall of central detail information in the emotional group compared to the unusual and neutral control groups. Yet in Experiments 1 and 3, the unusual condition sometimes outperformed the emotional group, especially on free recall. Thus, it appears that under slightly different experimental circumstances the outstanding, but not emotional, properties of a stimulus have a beneficial effect on central detail recall accuracy. However, the fact that this superiority of the unusual group was not consistent across the various recall measures precludes strong conclusions.

It should be noted that a recall failure carries a different meaning for the peripheral bicycle and the central girl. The peripheral bicycle was either mentioned or it was not. In addition, Experiment 1 demonstrated that peripheral recall was significantly correlated with eye fixation durations. Thus, a failure to report the peripheral bicycle may be indicative of an initial encoding failure due to attentional narrowing. Closer inspection of failures to report the central girl paints a different picture. While many subjects did not mention the girl explicitly, they indicated that they had seen someone in the critical slide. Thus, it is less likely that the central character was not encoded at all.

How should the complex pattern of results produced by the current experiments be interpreted? A first explanation is in terms of the type of instruction given to the subjects in combination with the type of recall task afterwards. In Experiment 2, subjects were merely instructed to attend closely to the slides, whereas Experiments 1 and 3 employed self-relevant identification instructions. Perhaps, then, these different instructions had ramifications for the encoding strategy employed by the subjects.

In processing accounts of memory (e.g. Craik, Govoni, Naveh-Benjamin, \& Anderson 1996; Roediger, Weldon, \& Challis, 1989), it is generally assumed that the extent to which people elaborate material during encoding influences the way in which they subsequently recall that material. Accordingly, it is conceivable that the extensive identification instructions of Experiments 1 and 3 led our subjects to engage in a top-down, schemabased encoding strategy. This might have been less the case for the subjects receiving "mere viewing" instructions in Experiment 2. Apart from encoding, it has been argued that recall performance depends on the type of subsequent 
testing (Blaxton, 1989; Roediger et al., 1989). Perhaps subjects who received "mere viewing" instructions predominantly inspected the physical properties of the presented stimulus material. The subsequent cued recall task, in which part of the visual information was reinstated, may have provided an appropriate constellation for retrieving colour information. Following this line of reasoning, one could argue that enhanced recall of central colour information in the emotional group of Experiment 2 may be due to the modulating effects of arousal-related brain processes (e.g. Cahill \& McGaugh, 1996; Cahill, Prins, Weber, \& McGaugh, 1994). In contrast, the identification instructions in Experiments 1 and 3 may have induced ruminations about how to integrate the target slide into the story rather than the encoding of perceptual features. The recall tasks, however, predominantly asked for specific perceptual information. Possibly, this mismatch precluded, or in case of the colour questions in Experiment 3, attenuated, differential recall patterns. In sum, then, the contrasting findings of Experiment 2 on the one hand, and Experiments 1 and 3 on the other hand, may be understood in terms of encoding emphasis induced by the experimental instructions. Of course, this interpretation is post-hoc and should be empirically evaluated.

A second explanation for our pattern of findings has to do with an important procedural difference between the experiments. In Experiment 2 , subjects were merely asked to recall the colours associated with the central and peripheral items of the target slide. In contrast, subjects in Experiments 1 and 3 performed a series of recall tasks, varying in level of specificity of the responses required. It may well be the case that while pertinent information is available in memory, the nature of the recall task is crucial for inviting its expression. In other words, even though subjects may know that they saw a young girl, this knowledge may not be as relevant for describing the target slide during free recall as the fact that she lay injured on the crossing. On a related note, the detailed cued recall test asked for specific, perceptual details associated with the central and peripheral items in the target slide. But as far as the central item is concerned, such information is not relevant to the theme of the slide story and therefore has a peripheral status in that respect. Thus, the idea that some information in memory is not expressed until it is specifically targeted may provide an explanation for our inconsistent results. Consider Experiment 3. For the detailed cued recall task, relatively general instructions were given to the subjects and differential recall patterns (i.e. an interaction of slide version and type of detail) were absent. In contrast, for the specific colour questions in that experiment, a tendency in the expected direction (i.e. differential recall in subjects who saw the emotional slide) did occur. On the other hand, post-hoc inspection of the number of subjects that spontaneously mentioned colour during detailed cued recall reveals that the emotional group displayed a slight advantage relative to the unusual group in mentioning the central colour. ${ }^{3}$ This indicates that an explanation in terms of recall task specificity cannot fully account for the current findings.

There were other procedural differences between the experiments that deserve some comment. To begin with, subjects in Experiments 1 and 3 were instructed that the goal of the study was measuring physiological reactions to slides. In contrast, subjects in Experiment 2 heard no cover story. Thus, expectations of a recall task may have influenced the results. On the other hand, it seems unlikely that subjects would specifically have expected a recall task involving colours. Even if they did, it is difficult to see why such expectations would promote differential recall in the emotional group. A more serious point is that the subjects in Experiments 1 and 3 performed various recall tasks, some of which involved all the slides that were seen. This may have interfered with their recall of perceptual information. For example, it may be argued that the mere act of retrieving perceptual information of the preceding seven slides hampered the accurate recall of colour information of the critical eighth slide.

Taken together, the absence of differential

${ }^{3}$ The percentages of subjects who spontaneously mentioned colour information during DCR were as follows. In the short stimulus duration condition, the colour of the blouse was mentioned by $23.3 \%, 3.3 \%$, and $20 \%$ of the emotional, unusual, and neutral groups, respectively. For the long stimulus duration condition, these percentages were 26.7 for the emotional, 6.7 for the unusual, and 16.7 for the neutral group. Separate logistic regression analysis showed that the contrast between the emotional and unusual groups reached significance, $B=-2.18$, se $=1.1, p<.05$. In the short stimulus duration condition, $13.3 \%$ of the emotional, $16.7 \%$ of the unusual, and $10 \%$ of the neutral group in the short stimulus duration condition mentioned the colour of the peripheral bicycle. For the long stimulus duration condition, these percentages were $13.3,36.7$, and 10 for the emotional, unusual, and neutral groups, respectively. A separate logistic regression analysis did not yeild significant main or interaction effects. 
recall patterns in Experiments 1 and 3 may be explained by instructional variables and/or procedural issues such as the number and type of recall tests employed. Future studies may establish if, and to what extent, both parameters contribute to (the absence of) differential recall in this type of experimental approach. However, the question arises of what the exact relevance of such an enterprise would be. The main purpose of Experiment 1 was exploring the underlying mechanism (i.e. attentional narrowing; Christianson, 1992) of a frequently observed phenomenon (i.e. enhanced central detail and impaired peripheral detail recall of emotional material) in eyewitness literature. This phenomenon was observed in different experiments, conducted in different laboratories with different stimulus materials (e.g. Burke et al., 1992; Christianson \& E.F. Loftus, 1991). A subsidiary aim of the present studies was to increase the ecological validity of the experimental approach to this phenomenon. Yuille and Tollestrup (1992) identified two closely related variables that critically differ between laboratory and real-life emotional situations, namely involvement of the subjects and emotional intensity. Manipulating the first variable by giving self-involvement instructions, however, resulted in radically different recall patterns than were anticipated. Thus, what seemed to be a robust phenomenon, turned out to be a result that critically depends on rather specific experimental circumstances. This raises questions about the extent to which emotional memory can be studied with experiments relying on normal subjects viewing relatively unobtrusive slides. To be sure, the experimental approach is essential for studying possible underlying mechanisms of the observed phenomena. Therefore, we suggest that rather than putting effort and resources into pinpointing the exact experimental parameters that produce the desired phenomenon in normal subjects, it may be more worthwhile to invest in other methods that seek to increase emotional intensity in an ethically acceptable manner. Research from our laboratory (Wessel \& Merckelbach, 1997, 1998) indicates that confronting phobics with their feared object, thereby indicating relatively high levels of emotion, might provide such an alternative method. This may offer a more promising approach for testing the attentional narrowing hypothesis of emotional memory.

Manuscript received 4 May 1998 Manuscript accepted 9 June 1999

\section{REFERENCES}

Blaxton, T.A. (1989). Investigating dissociations among memory measures: Support for a TransferAppropriate Processing framework. Journal of Experimental Psychology: Learning, Memory, and Cognition, 15 657-668.

Burke, A. Heuer, F., \& Reisberg, D. (1992). Remembering emotional events. Memory and Cognition, 20, 277-290.

Cahill, L., \& McGaugh, J.L. (1996). Modulation of memory storage. Current Opinion in Neurobiology, 6, 237-242.

Cahill, L. Prins, B., Weber, M. \& McGaugh, J.L. (1994). B-Adrenergic activation and memory for emotional events. Nature, 371,702-704.

Christianson, S.-A. (1992). Emotional stress and eyewitness memory: A critical review. Psychological Bulletin, 112, 284-309.

Christianson, S.-A., \& Loftus, E.F. (1987). Memory for traumatic events. Applied Cognitive Psychology, 1, 225-239.

Christianson, S.-Å, \& Loftus, E.F. (1990). Some characteristics of people's traumatic memories. Bulletin of the Psychonomic Society, 28, 195-198.

Christianson, S.-A., \& Loftus, E.F. (1991). Remembering emotional events: The fate of detailed information. Cognition and Emotion, 5, 81-108.

Christianson, S.-A., Loftus, E.F., Hoffman, H., \& Loftus, G.R. (1991). Eye fixations and memory for emotional events. Journal of Experimental Psychology: Learning, Memory and Cognition, 17, 693701 .

Craik, F.I.M, Govoni, R, Naveh-Benjamin, M, \& Anderson, N.D. (1996). The effects of divided attention on encoding and retrieval processes in human memory. Journal of Experimental Psychology: General, 125, 159-180.

Easterbrook, J.A. (1959). The effect of emotion on cue utilization and the organization of behavior. Psychological Review, 66, 183-201.

Heuer, F., \& Reisberg, D. (1990). Vivid memories of emotional events: The accuracy of remembered minutiae. Memory and Cognition, 18, 496-506.

Heuer, F., \& Reisberg, D. (1992). Emotion, arousal, and memory for detail. In S.-Å. Christianson (Ed.) Handbook of memory and emotion: Theory, research and practice (pp.151-180). Hillsdale, NJ. Lawrence Erlbaum Associates Inc.

Hosmer, D.W., \& Lemeshow, S. (1989). Applied logistic regression. New York: Wiley.

Hunt, R. (1995). The subtlety of distinctiveness: What von Restorff really did. Psychonomic Bulletin and Review, 2, 105-112.

Loftus, E.F., Loftus, G.R., \& Messo, J. (1987). Some facts about "weapon focus". Law and Human Behavior, 11, 55-62.

Loftus, G.R. (1972). Eye fixations and recognition memory for pictures. Cognitive Psychology, 3, 525551.

Loftus, G.R., \& Mackworth, N.H. (1978). Cognitive determinants of fixation location during picture viewing. Journal of Experimental Psychology: Human Perception and Performance, 4, 565-572. 
Pickel, K.L. (1998). Unusualness and threat as possible causes of "weapon focus". Memory, 6, 277-295.

Roediger, H.L III, Weldon, M.S., \& Challis, B.H. (1989). Explaining dissociations between implicit and explicit measures of retention: A processing account. In H.L. Roediger III \& F.I.M. Craik (Eds.), Varieties of memory and consciousness: Essays in honour of Endel Tulving (pp.3-41). Hillsdale, NJ: Lawrence Erlbaum Associates Inc.

Terr, LC. (1994) Unchained memories: True stories of traumatic memories, lost and found. New York: Basic Books.

Wessel, I., \& Merckelbach, H. (1994). Characteristics of traumatic memories in normal subjects. Behavioural and Cognitive Psychotherapy, 22, 315-324.

Wessel, I., \& Merckelbach, H. (1997). The impact of anxiety on memory for details in spider phobics. Applied Cognitive Psychology, 11, 223-231.

Wessel, I., \& Merckelbach, H. (1998). Memory for threat-relevant and threat-irrelevant cues in spider phobics. Cognition and Emotion, 12, 93-104.

Yuille, J.C., \& Tollestrup, P.A. (1992). A model of the diverse effects of emotion on eyewitness memory. In S.-Å. Christianson (Ed.), Handbook of memory and emotion: Theory, research and practice (pp.201-215). Hillsdale, NJ: Lawrence Erlbaum Associates Inc.

\section{APPENDIX}

Tape-recorded instruction giving the background of the story depicted in the slide series:

You are a student in Health Sciences. You are living with several people in a student dorm. You like it there: you are always having a good time. In fact, you are having such a good time, that you spend too little time studying. Recently, you failed an exam for that reason. Only a few people failed the exam Therefore, the professor did not think it was necessary to give another written test, but decided to give an oral exam. This time, you are well prepared and you feel confident that you will pass. Today is the day of the exam. Your appointment is at $10.30 \mathrm{am}$. It is now morning and you just woke up. You slept well and you feel rested. This is what you see: 